\title{
Production of Biopolymers by Pseudomonas aeruginosa Isolated from Marine Source
}

\author{
Nazia Jamil $^{1} *$ and Nuzhat Ahmed ${ }^{2}$ \\ ${ }^{I}$ Microbiology and Molecular Genetics; University of the Punjab; jamil_nazi@yahoo.com; Lahore 54590; Pakistan. \\ ${ }^{2}$ Centre for Molecular Genetics; University of Karachi; Karachi 75270; Pakistan
}

\begin{abstract}
Two bacterial strains, Pseudomonas aeruginosa CMG607w and CMG1421 produce commercially important biopolymers. CMG607w isolated from the sediments of Lyari outfall to Arabian Sea synthesize the mclpolyhydroxyalkanoates from various carbon sources. The production of PHAs was directly proportional to the incubation periods. Other strain CMG1421, a dry soil isolate, produced high viscous water absorbing extracellular acidic polysaccharide when it was grown aerobically in the minimal medium containing glucose or fructose or sucrose as sole source of carbon. The biopolymer had the ability to absorb water 400 times more than its dry weight. This property was superior to that of currently used non-degradable synthetic water absorbents. It acted as salt filter and had rheological and stabilizing activity as well.
\end{abstract}

Key words: Biopolymers, exopolysaccharides, hydroabsorbent, mcl-polyhydroxyalkanoates, Pseudomonas aeruginosa, Sodium gluconate

\section{INTRODUCTION}

Biopolymers such as the Polyhydroxyalkanoates (PHAs) and the Exopolysaccharides (EPS) are diverse and versatile class of the materials that have potential applications in virtually all sectors of the economy. In response to the increasing public concern about the harmful effect of the petrochemical derived plastic materials in the environment, many countries are looking for alternate source such as biodegradable plastic materials. These materials must retain the desired material properties of the conventional synthetic plastics, and should be able to degrade on disposal. PHAs are polyesters of various hydroxyalkanoates, which are synthesized by the microorganisms. They are considered to be strong candidate for biodegradable polymer as they possess all the properties of synthetic plastic and when discarded are completely degraded to water and carbon dioxide by microorganisms (Lee, 1996). The fluorescent Pseudomonas belonging to the rRNA homology group I have been reported to synthesize and accumulate large amount of medium chain length polyhydroxyalkanoates (mclPHA) consisting of various saturated 3-hydroxy fatty acids with carbon ranging from 6 to 14 carbon atoms and they act as energy storage compound. The PHA comprising of medium chain monomers (6 or more carbon length) is more elstomeric and may contain unsaturated carbon bonds. They are more conducive for coating and film materials and offer greater possibilities for the chemical modifications (Anderson and Dwes, 1990).

The modernization in the life style has increased the use of various kinds of the sanitary products including disposable baby diapers. Most of the

*Author for correspondence 
water absorbing materials being currently used in these products are made up of synthetic organic compounds and their derivatives such as polyacrylate, polyacrylamide, acrylic acid and acrylamide, etc. These synthetic absorbing polymers are nondegradable, harmful (Merck Index) and carcinogenic (Ryuichiro and Nohata, 1994) for human beings. Hence, when these are discharged and disposed, they remain in the environment for long periods, thus contributing to the environmental pollution (Ryuichiro and Nohata, 1994). However, the natural water absorbing compounds such as the bacterial exopolysaccharides are environment friendly, nontoxic to human, animals and microorganisms and are degradable by the microorganisms. Present study was conducted to isolate the bacterial strains able to synthesize commercially important biopolymers, to optimize their production and to study the chemical nature of these polymers.

\section{MATERIALS AND METHODS}

\section{Isolation, purification and cultural conditions}

A sample of the sediment from the western beach near the Lyari outfall was collected from Karachi coast (around $47.21^{\circ} \mathrm{N} 67.10^{\circ} \mathrm{E}$ ). The bacterial strain was isolated, purified and coded as CMG607w, while the strain CMG1421 was isolated from the dry soil, Karachi University; it was also purified and both were preserved in $20 \%$ glycerol at $-70^{\circ} \mathrm{C}$. The strains were identified by using the API kit and were found to be $P$. aeruginosa. Strain CMG607w was maintained at $30^{\circ} \mathrm{C}$ in artificial sea water (ASW) (Kuniho and Kurane, 1999) in 1 L of distilled water, supplemented with $0.5 \mathrm{~g}$ tryptone and $10 \mathrm{~g}$ carbon source (glucose/sucrose/ sodium acetate or sodium gluconate). For the PHA synthesis, same cultural conditions were used and the incubation time was increased from 24 to $120 \mathrm{~h}$ at $30^{\circ} \mathrm{C}$ and $200 \mathrm{rpm}$. For the synthesis of the hydroabsorbent polysaccharide, CMG1421 was grown in the minimal medium as described by Ryuichiro and Nohata (1994), supplemented with $20 \mathrm{~g} / \mathrm{L}$ carbon source. After growing in the same minimal medium, $1 \mathrm{ml}$ (48 $\mathrm{h}$ old) seed culture was inoculated into $1 \mathrm{~L}$ minimal medium and incubated at $30^{\circ} \mathrm{C}$ for 15 days.

\section{Extraction and purification of Biopolymers}

The lyophilized cell material was used for the PHA extraction with chloroform at $65^{\circ} \mathrm{C}$ for $4 \mathrm{~h}$ in the screw cap bottles. The extraction was done three times from the same material. The cell debris were removed by passing through a cellulose filter and the chloroform solution was concentrated by using a rotary evaporator (BUCHI Rotavapor R114, Switzerland). The polymer was precipitated by pouring the chloroform solution (1 volume) into ethanol (5 volumes). The precipitated polymer was separated from the liquid by the filtration and was dried by exposure to hot air. The precipitation was repeated for further purification and used for the chemical analysis.

The viscous culture broth of CMG1421 was diluted (Kuniho and Kurane, 1999) with half volume of sterilized distilled water and placed in shaking incubator $\left(30^{\circ} \mathrm{C}\right)$ for one hour. The bacterial cells were sedimented by centrifugation at $10,000 \mathrm{rpm}$ for $30 \mathrm{~min}$ at $4^{\circ} \mathrm{C}$ using KOKUSAN $\mathrm{H}-200 \mathrm{nR}$ refrigerate centrifuge. Trichloro acetic acid (TCA) $5-10 \%$ was added to the cell-free supernatant to precipitate the extracellular protein fractions. Then it was centrifuged at 9,000 rpm for $30 \mathrm{~min}$ at $4^{\circ} \mathrm{C}$ to collect the protein fractions. The clear supernatant was added to equal volume of absolute ethanol (Hiroyasu et al, 1992). The precipitates were collected around the glass rod. The dissolution and precipitation process was carried out four to five times until the uniform white precipitates were obtained. The sample was dried in the wheaten dry-seal vacuum desiccators. The crude hydroabsorbent was dialyzed against the distilled water and lyophilized.

\section{Quantification and structure elucidation of PHA}

The Quantification of the PHA produced by the CMG607w was determined by Slepecky and law method (1961). For the structure elucidation, the purified PHA was dissolved in the chloroform and layered on the KRS-5 window. After the evaporation of the chloroform the PHA polymer film was subjected to the FTIR (Fourier transmison infra red) analysis. The infrared spectra was recorded on JASCO 320-A spectrometer with a beam condenser and the spectra range used was $5000-330 \mathrm{~cm}^{-1}$. The purified PHA was also analyzed by using $300-\mathrm{MHz}{ }^{1} \mathrm{H}-\mathrm{NMR}$ (protonnuclear magnetic resonance) spectrophotometer. A $0.5 \%(\mathrm{w} / \mathrm{v})$ polymer in ( $d$-chloroform) $\mathrm{CDCl}_{3}$ ) spectrum was recorded at temperature $298 \mathrm{~K}$. ${ }^{1} \mathrm{H}$ - 
NMR peaks areas were determined by spectrometer integrations.

\section{Chemical composition of EPS}

The chemical composition of the dialyzed samples from the CMG1421 was determined in terms of total contents of the following; carbohydrate by anthrone-sulphuric acid assay (Spiro, 1966) and phenol-sulphuric acid assay(Kochert, 1978), amino sugars by Elson-Morgan assay (Dey and Harborne, 1990), protein by Bradford method (1978), phosphate by George et al method (1974), and acidic sugars (uronic acid) by Carbazol assay (Bradford, 1978).

\section{Water absorption capacity}

The water absorption capacity of the purified bioabsorbent was determine by "the tea bag method" (Ryuichiro and Nohata, 1994). The dried and labeled tea bag was filled with $20 \mathrm{mg}$ sample, and each of them was immersed into $200 \mathrm{ml}$ distilled water and $\mathrm{NaCl}$ solutions contained in beakers and left for 2, 4 and $6 \mathrm{~h}$. Besides the biopolymer, ten other controls samples i.e. xanthan gum, sodium alginate, agar, cellulose, ion exchange resin, anionic high-polymer absorbent (Diafloc IncP-MP), silica gel, high grade synthetic high-polymer absorbent (Sumika Co., Gel S-50), soil and empty tea bags were also tested for their water absorption capacity. The maximum water absorption capacity (g) per gram of dried samples was calculated in terms of average.

\section{Moisture absorption capacity}

The moisture absorption capacity was also determined by the method of Ryuichiro and Nohata (Ryuichiro and Nohata, 1994). Wheaton dryseal vacuum desiccators containing the saturated solutions of magnesium chloride was used at relative humidities of $61.8 \%$ while being stored at $37^{\circ} \mathrm{C}$ in an incubator for 2, 6, 24 and $72 \mathrm{~h}$.

\section{Water retention capacity}

The Water retention capacity was measured by the "glass column method" (Ryuichiro and Nohata, 1994). The dried (100 mg) hydroabsorbent synthesized in the presence of sucrose, sodium alginate, xanthan, synthetic acrylamide high polymer was mixed with $100 \mathrm{~g}$ of dried sand and packed in each column. The amount $(\mathrm{g})$ of water retained by each sample was estimated for $10 \mathrm{~min}$, 1,10 and $24 \mathrm{~h}$ at $60^{\circ} \mathrm{C}$ with $50-60 \%$ relative humidity.

\section{Moisture retention capacities}

A100 mg of the vacuum dried and heat dried $\left(110^{\circ} \mathrm{C}\right)$ hydroabsorbent (in the presence of sucrose) sample, $\mathrm{CaCl}_{2}$, silica gel, glycerin, urea, anionic polymer, were weighed. $30 \mu \mathrm{l}$ distilled water was added to each sample and then left at $60^{\circ} \mathrm{C}$. Each sample was weighed after 1, 2, 5, 10 and 15 days and moisture retention capacities of each sample were calculated as average of three adjacent values (Ryuichiro and Nohata, 1994).

\section{RESULTS}

\section{PHA accumulation and chemical analysis}

$P$. aeruginosa CMG607w was able to utilize glucose, sucrose, sodium acetate and sodium gluconate as carbon source under the aerobic conditions. Strain CMG607w grew efficiently in the chemically defined media supplemented with sodium gluconate and showed exponential phase of about $25 \mathrm{~h}$ with high cell density while in the presence of glucose/sodium acetate/sucrose, the exponential phase was of $20 \mathrm{~h}$ with low cell density. The PHA extracted from CMG607w was in the form of white precipitates in the presence of all the tested carbon sources but in the presence of sodium gluconate, the amount of PHA produced was higher as compared to that of other carbon sources.

Table 1 - PHA synthesis by CMG607w from sodium gluconate in shake flask cultures.

\begin{tabular}{ccccc}
\hline Time & $\mathbf{p H}$ & $\begin{array}{c}\text { Lyophilized cell wt } \\
(\mathbf{m g} / \mathbf{L})\end{array}$ & PHA con. $(\mathbf{m g} / \mathbf{L})$ & $\begin{array}{c}\text { PHA } \\
\text { content }(\mathbf{w t} \%)\end{array}$ \\
\hline 24 & 6.2 & 243 & 56 & 23.0 \\
48 & 6.0 & 690 & 213 & 30.8 \\
72 & 5.3 & 889 & 376 & 42.3 \\
\hline
\end{tabular}


In the presence of $1 \%$ sodium gluconate, it synthesized $56 \mathrm{mg} / \mathrm{L}$ of PHA after $24 \mathrm{~h}$ while the maximum production of PHA was $376 \mathrm{mg} / \mathrm{L}$ after the $72 \mathrm{~h}$. With the increase in the incubation time, the PHA content in the cells tended to increase and reached to $42.3 \mathrm{wt} \%$ of the dry cell mass (Table 1). The purified PHA showed strongest band at $1735 \mathrm{~cm}^{-1}$ for the carbonyl easter group in the FTIR spectra (Fig.1).

The methylene $\left(\mathrm{CH}_{2}\right)$ vibration near $2925 \mathrm{~cm}^{-1}$ was also observed. The purified PHA isolated from the cells grown in the media with sodium gluconate when analyzed by using $300-\mathrm{MHz}{ }^{1} \mathrm{H}-\mathrm{NMR}$ spectrometer (Fig. 2) showed that the mcl-PHA was the major composition. The integration values agreed well with the proposed polymer structure
(Ohyoung et al, 1995). The ${ }^{1} \mathrm{H}-\mathrm{NMR}$ spectra showed the characteristic methyl, methylene and methine protons of the PHA. The most upfield triplet of the methyl appeared at $\delta 0.87(\mathrm{~J}=6.6 \mathrm{~Hz})$ and the octet appearing at $\delta 2.42-2.62\left(\mathrm{~J}_{\mathrm{AX}}=5.7 \mathrm{~Hz}\right.$, $\left.\mathrm{J}_{\mathrm{BX}}=7.4 \mathrm{~Hz}, \mathrm{~J}_{\mathrm{AB}} 15.5 \mathrm{~Hz}\right)$ was due to methylene $(\mathrm{H}-$ a). A broad singlet of $18{ }^{1} \mathrm{H}$ integration appearing at $\delta 1.25$ was assigned to $(\mathrm{H}-\mathrm{d})$. In the same spectrum, one broad singlet of two proton integration resonated at $\delta 1.58$ and was assigned to $\mathrm{H}$-e. The down field multiplet resonating at $\delta 5.23$ was due to the only methane. All the chemical shifts were confirmed by comparison with the reported data (Ohyoung et al, 1995).

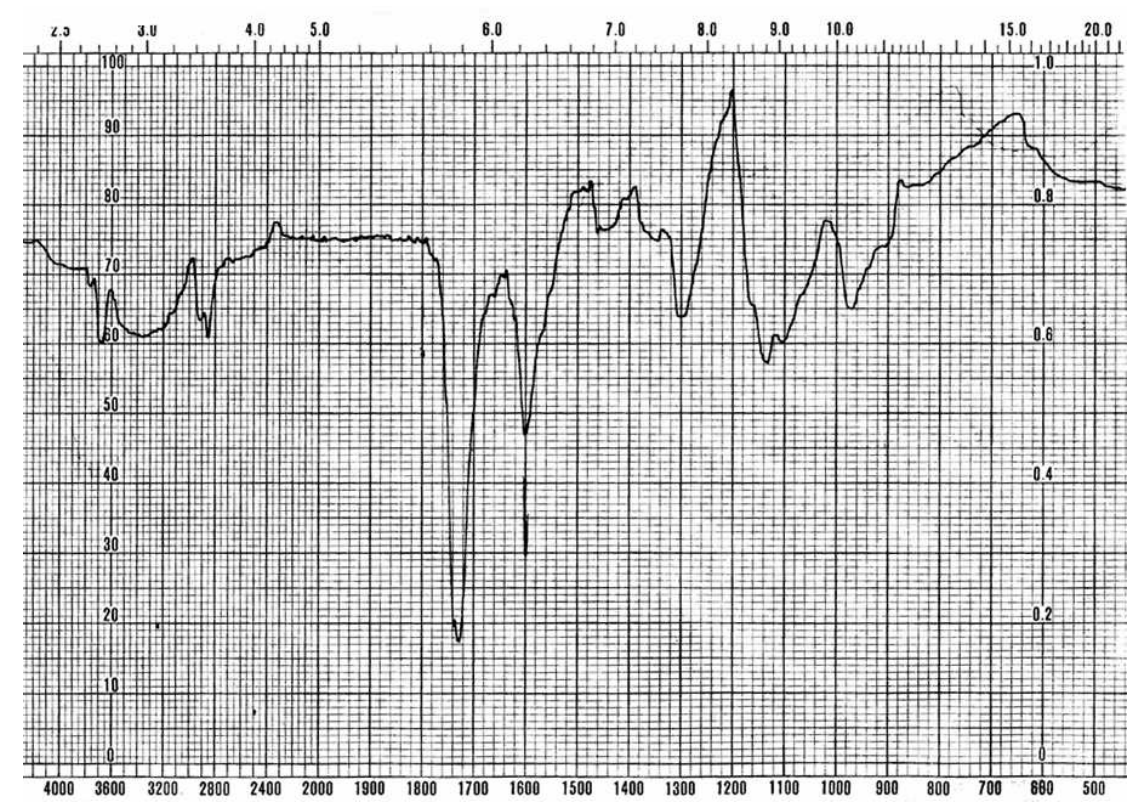

Figure 1 - FT-IR Spectra of purified mcl-PHA from CMG607w

\section{EPS production and chemical analysis}

The ethanolic precipitation showed that the insoluble precipitates were flocculent of high molecular weight compounds. In the absence of urea, the viscosity of the culture was significantly decreased which has suggested that urea enhanced the synthesis of the polymer. The analysis of the chemical composition of the biopolymer produced using glucose/ fructose or sucrose showed that the total carbohydrates were $95.73,96.86$ and $97.06 \%$; uronic acid was 2.15 , 2.91 and $2.78 \%$ respectively. A trace amount of $\mathrm{PO}_{4}$ was also detected in all the samples (Table 2). 
Table 2 - Chemical composition of hydroabsorbent biopolymer (contents expessed as $\mu \mathrm{g} \% \mathrm{w} / \mathrm{w}$ ).

\begin{tabular}{lccccc}
\hline Samples & Carbohydrate & Protein & $\begin{array}{c}\text { Amino } \\
\text { Sugars }\end{array}$ & $\begin{array}{c}\text { Uronic } \\
\text { acid }\end{array}$ & PO $_{\mathbf{4}}$ \\
\hline bpS & & & - & 2.15 & 0.728 \\
bpF & 95.732 & - & - & 2.908 & 0.515 \\
bpG & 96.856 & - & - & 2.776 & 0.065 \\
\hline
\end{tabular}

bpS: Biopolymer obtained when sucrose was used as carbon source

$\mathrm{bpF}$ : Biopolymer obtained when fructose was used as carbon source

bpG : Biopolymer obtained when glucose was used as carbon source

Table 3 - Water absorption (\%) of various absorbents per gram of sample.

\begin{tabular}{|c|c|c|c|c|c|c|}
\hline \multicolumn{3}{|c|}{ Without NaCl } & \multicolumn{4}{|c|}{$\mathrm{NaCl}(\%)$} \\
\hline Groups & Sample & Dst.water & 0.89 & 2 & 4 & 6 \\
\hline \multirow{4}{*}{$\begin{array}{l}\text { Test } \\
\text { group }\end{array}$} & bpS & 432.65 & 245.31 & 185.33 & 139.13 & 85.0 \\
\hline & $\mathrm{bpG}$ & 426.5 & 200.11 & 153 & 123 & 74.54 \\
\hline & $\mathrm{bpF}$ & 422.0 & 205.56 & 145.74 & 130.44 & 70.78 \\
\hline & $\begin{array}{c}\text { High } \\
\text { grade } \\
\text { synthetic }\end{array}$ & 244.72 & 112.51 & 92.81 & 67.0 & 39.75 \\
\hline \multirow{6}{*}{$\begin{array}{l}\text { Control } \\
\text { group }\end{array}$} & $\begin{array}{l}\text { Anionic } \\
\text { synthetic }\end{array}$ & 348.33 & 135.54 & 103.53 & 85.33 & 47.87 \\
\hline & Alginate & 78.83 & 47.45 & 34.35 & 28.78 & 27.68 \\
\hline & Xanthan & 77.0 & 45.56 & 34 & 30.77 & 27.89 \\
\hline & cellulose & 45.75 & 35.23 & 24.95 & 23 & 20.42 \\
\hline & $\begin{array}{c}\text { Ion } \\
\text { exchange } \\
\text { resin } \\
\end{array}$ & 9.1 & 5.68 & 2.34 & 2.0 & 2.2 \\
\hline & Soil & 2.44 & 2.33 & 2.43 & 2.12 & 2.0 \\
\hline
\end{tabular}

Table 4 - Retention capacity (\%) of supplied water to mixture of hydroabsorbent and Sand under different time intervals.

\begin{tabular}{lcccc}
\multicolumn{1}{c}{ Samples } & 10min & 1h & 12h & 24h \\
\hline bpS & 97 & 87 & 51 & 38 \\
Xanthan & 10 & 5 & 0 & 0 \\
Cellulose & 11 & 4 & 0 & 0 \\
Alginate & 12 & 8 & 8 & 8 \\
Polyacrylamide & 17 & 3 & 3 & 0 \\
Synthetic high & 9 & 5 & 5 & 1 \\
polymer absorbent & & & & \\
\hline
\end{tabular}

\section{Hydroabsorbent properties of EPS}

Results of the water absorbing properties of the biopolymer revealed that the biopolymer absorbed 400 times more water than its own weight which was much higher when compared with that of commercially available water absorbing compounds, i.e. high grade synthetic high-polymer absorbent and anionic high-polymer absorbent whose absorption capacities were 244 and 348 times of their dried weight, respectively. The water absorption capacity of the present hydroabsorbent was 3-5 times higher than that of commercially available polysaccharide gums, such as xanthan, alginate and cellulose (Table 3). When the saline 
conditions were developed, the water absorption capacity was decreased with an increase in the concentration of $\mathrm{NaCl}$ (Table 3) but this reduced capacity was still superior to the absorption capacity of the control samples.

In the presence of $61.8 \%$ moisture, the bacterial hydroabsorbents (bpS, bpF, bpG) were capable to absorb 26-31\% moisture, which was also superior to those of the control polysaccharides (xanthan, alginate and cellulose). $\mathrm{CaCl}_{2}$, and Glycerin showed higher moisture absorption than the test hydroabsorbent but $\mathrm{CaCl}_{2}$ became liquefied after the saturation at $72 \mathrm{~h}$ this was, however, not observed with under study bioabsorbent (Fig. 3).

When the hydroabsorbent polymer and synthetic water absorbents with the soil were subjected to the lab scale desert environmental conditions (50$60 \%$ relative humidity, $60^{\circ} \mathrm{C}$ ) for the retention capacity of supplied water, it was observed that the hydroabsorbent polysaccharide could retain 38\% of supplied water for $24 \mathrm{~h}$ (Table 5). While the synthetic high absorbent and polyacrylamide could not retain the supplied water in same conditions, only alginate could retain $8 \%$ water (Table 4 ).

\section{DISCUSSION}

The use of the synthetic polymers has become a common practice in our daily life. These polymers have made the life easy, e.g. the use of plastic bags, bottles, tissues papers, baby diapers, etc. On one hand, they have made the life easy but on the other hand, they are responsible for a great contribution in the environmental pollution. On disposal, these polymers do not degrade and remain in the environment. Realizing this situation, the scientists are now looking for the alternate source such as biopolymers.

The production of PHA by CMG607w showed that the PHA was accumulated in large quantities in the cells (unpublished data), after the cessation of growth and nutrient unbalance conditions (Lee, 1996). PHA accumulation after $24 \mathrm{~h}$ was $23 \mathrm{wt} \%$ of cell dry mass while after $72 \mathrm{~h}$ of incubation it reached to $42.3 \mathrm{wt} \%$ of cell dry mass. Purified
PHA showed strongest band at $1735 \mathrm{~cm}^{-1}$, in comparison, to PHA being produced A. zotobacter vinelandii and Pseudomonad mendocina their carbonyl bands $(\mathrm{C}=\mathrm{O})$ at $1732 \mathrm{~cm}^{-1}$ (Hong et al, 1999). In the presence of sodium gluconate mclPHA was identified by $\mathrm{H}^{+} \mathrm{NMR}$, hence it was

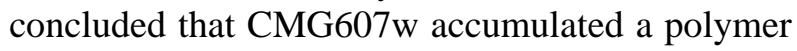
with medium chain length as the major constituent when the cells were grown on sodium gluconate (Huijbert et al, 1992). The strains producing $40 \%$ or more mcl-PHAs are considered to be the good candidates for the commercial exploitations (Harbak, 1992). The CMG607w could have the economical advantage that it used the inexpensive carbohydrate derived substrate (gluconate) as the sole carbon source for the mcl-PHA production.

The CMG1421 produced an extracellular polysaccharide in the minimal broth. The polysaccharide made the broth very viscous, which consisted of mainly carbohydrate. Further more, the chemical composition was suggested that bacterial biopolymer was acidic polysaccharide in nature (Table 2). The dried weight of extracellular biopolymer was found in the range of $2-4 \mathrm{~g}$ per liter of the broths. The polymer was found to be insoluble in tap water, hot water $\left(60^{\circ} \mathrm{C}\right)$, distilled water and saline; this suggested that the bacterial biopolymer was tolerant against different environmental conditions (Table 5).

This polysaccharide absorbed 3-4 hundred times more water as compared to its own weight which was superior to that of compounds as bioabsorbents used as controls (Table 3). It showed that the polymer was insoluble hydrophilic compound and acted as water reservoir. In the presence of $\mathrm{NaCl}$, reduction was observed in the water absorbing capacity but the capacity of hydroabsorbent was still significant as compared to those of controls. The reason for the reduction in the water absorption of the polymer in salty conditions could be that this polymer acted as a salt filter and sections of the polymer eventually were saturated with the salt, hence, a reduction in the water absorption was observed (Moazami, 2001). 
Table 5 - Moisture retention capacities (\%) of different absorbents under relative temperature $60^{\circ} \mathrm{C}$.

\begin{tabular}{|c|c|c|c|c|c|c|}
\hline \multirow[t]{2}{*}{ Sample } & \multicolumn{6}{|c|}{ Moisture retention at given intervals (days) } \\
\hline & 0 & 1 & 2 & 5 & 10 & 15 \\
\hline $\mathrm{bpS}$ & 100 & 76 & 70 & 72 & 58 & 47 \\
\hline $\mathrm{CaCl}_{2}$ & 100 & 78 & 73 & 68 & 60 & 45 \\
\hline $\begin{array}{l}\text { Silica } \\
\text { beads }\end{array}$ & 100 & 50 & 40 & 25 & 17 & 12 \\
\hline Glycerin & 100 & 62 & 44 & 29 & 13 & 13 \\
\hline Urea & 100 & 33 & 7 & 7 & 2 & 2 \\
\hline $\begin{array}{l}\text { Anionic } \\
\text { polymer }\end{array}$ & 100 & 41 & 25 & 22 & 22 & 22 \\
\hline $\begin{array}{l}\text { Plastic } \\
\text { cup }\end{array}$ & 100 & 0 & 0 & 0 & 0 & 0 \\
\hline
\end{tabular}

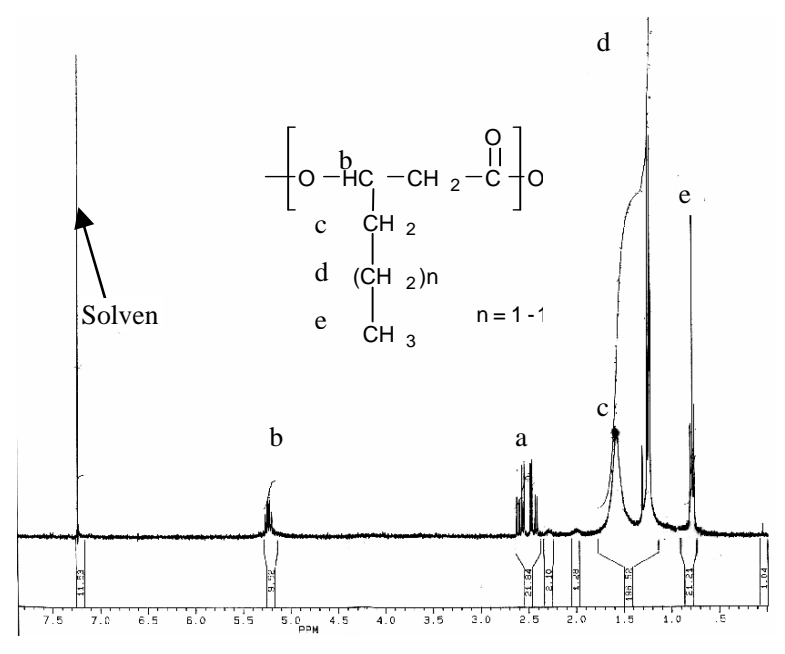

Figure 2 - The $300-\mathrm{MHz}{ }^{1} \mathrm{H}-\mathrm{NMR}$ spectrum was recorded in $d$-chloroform of the PHA produce by $P$. aeruginosa $\mathrm{CMG} 607 \mathrm{w}$ using Na-gluconate as carbon source

A similar type of the bacterial exopolysaccharide was reported by Moazami (2001) as super water absorbent for the revival of saline and desert lands which acted as water reservoir, salt filter and biofertilizer simultaneously. The studied hydroabsorbent biopolymer also showed the highest capacity of water retention inspite of dry and hot conditions created in the lab, suggesting that the biopolymer acted against water evaporation. Similarly the polymer demonstrated a significant moisture absorption and retention capacity in different relative environmental humidities (hot desert conditions), which was comparable to those of currently used desiccant compounds, i.e. $\mathrm{CaCl}_{2}$, glycerin and silica gel beads, thus it could be used as desiccant. Such type of bacterial exopolysaccharide have also been reported by Ryuichiro and Nohata (1994) which were produced by Alcaligene latus. The rheological characteristics of the biopolymer could be used for the stabilization of the soil and to prevent the soil erosion and high rate of evaporation in hot seasons. 


\section{REFERENCES}

Anderson, A.J., Dwes E.A. (1990), Occurrence, metabolism, metabolic role and industrial uses of bacterial Polyhydroxyalkanoates. Microbiol.Rev., 54, 450-472.

Bitter, T., Muir H. M. (1962), A modified uronic acid carbazole reaction. Anal. Biochem., 4, 330-334.

Bradford, M.M. (1978), A rapid and sensitive method for the quantitation of microgram quantities of protein utilizing the principle of protein-dye binding. J. Anal. Biochem., 72, 248-254.

Dey, P. M., Harborne J.B. (1990), Methods in plant biochemistry. In- Jovanovich Carbohydrates, ed. $\mathrm{H}$. Brace. Academic press Publishers, London, UK, pp. 2, 8-9.

Georg, K., William H.J. (1974), Hand book of Micromethods for the Biological Sciences. Van Nostran, Reinbold Company, pp. 91.

Hiroyasu, K.Y., Isobe, M., Horibe, J., Tokuda, I., Tokuno, K. and Kawal, F. (1992), Production of a novel extracellular polysaccharide by a Bacillus strain isolated from soil. Biosci, Biotech, Biochem., 56(6), 853-857.

Hong, T., Sun, S., Tian, W., Chen, G.Q. and Huang, W. (1999), A rapid method for detecting bacterial Polyhydroxyalkanoates in intact cells by Fourier transform infrared spectroscopy. Appl Microbiol. Bitechnol., 51, 523-526.

Hrabak, O. (1992), Industrial production of poly- $\beta$ hydroxybutyrate. FEMS Micobiol Rev., 103, 251-256.

Huijberts, G.N.M., Eggink, G., de Waard, P., Huisman, G.W., Witholt, B., (1992) Pseudomonas putida KT2442 cultivated on glucose accumulates poly(3hydroxyalkanoates) consisting of saturated and unsaturatedmonomers. Appl. Environ. Microbiol., 58, 536-544.
Kochert, G. (1978), Carbohydrate by phenol-sulphuric acid method. In- Physiological and biochemical methods, ed. J. A. Hellebust , L. S. Caigie, Cambridge University Press, Cambridge, pp. 96-97.

Kuniho, N, and Kurane, R. (1999), Production of extracellular polysaccharide bioflocculant by Klebsiella pneumoniae. Biosci, Biotech. Biochem., 63(12), 2064-2068.

Lee, S.Y. (1996), Bacterial Polyhydroxyalkanoates. Biotechnol.Bioeng.49, 1-14

Moazami, N. (2001), Revival of saline and desert lands using biofertilizers, mycorrhizae, biopolymer superwater absorbent and biosaline agriculture. In First international conference on biotechnology applications for the arid regions, State of Kuwait, ed. A. Yousif, A. Shayji, S..Jiwan M. Sidhu, Kouider Guerinik Published by Kuwait Institute for Scientific Research. pp 289-293.

Ohyoung, K. Richard, A. and Denise, R. (1995), Bioenergineering of poly ( $\beta$-hydroxyalkanoates) for advanced material applications: incorporation of cyano and nitrophenoxy side chain substituents. Can. J. Microbiol., 41(1), 32-43.

Ryuichiro, K. and Nohata, Y. (1994), A new waterabsorbing polysaccharide from Alcaligenes latus. Biosci, Biotech, Biochem., 58(2), 235-238.

Law, J.H. and Slepecky, R.A. (1961), Assay of Poly- $\beta$ hydroxbutyric acid. J. Bacteriol.,. 82, 33-36.

Spiro, R.G. (1966), Analysis of sugars found in glycoprotiens. Methods Enzymol., 8, 3-26.

Suwanoh, E.R. (1991), Correlation between possession of a Respiration Dependant $\mathrm{Na}+$ pump and $\mathrm{Na}+$ Requirement for growth of marine Bacteria. Appl. Environ. Microbiol,. 611,1844-1846.
Received: May 25, 2006; Revised: June 11, 2007; Accepted: January, 01, 2008. 